\title{
FILIGRANAS DEL ARCHIVO MUNICIPAL DE CÓRDOBA (1450-1550)
}

\section{RICARDO CÓRDOBA DE LA LLAVE - MANUEL CEREZO VILLEGAS Universidad de Córdoba}

La proliferación y variedad de las filigranas o marcas de agua es una de las características más llamativas de los diferentes tipos de papeles utilizados para la redacción de documentos en el curso de los siglos XV y XVI. Desde hace ya algún tiempo, diversos investigadores han destacado su importancia por lo que se refiere a la posibilidad de fechar a través de ellas documentos sin data, saber el momento en que se redactó una copia y conseguir, en líneas generales, un mejor conocimiento de la industria del papel en la época: lugares de origen, zonas de empleo, período de actividad de los molinos papeleros, relaciones comerciales que posibilitaron su difusión, etc. (1) Además de la información de carácter diplomático que las filigranas nos facilitan, ellas mismas tienen un valor intrínseco en absoluto desdeñable como testimonios gráficos de una época para la cual son tan escasos: martillos, tijeras, cuchillos, espadas, fuelles y un sinfín de útiles de trabajo han quedado registrados en ellas, asi como anclas, arcos, candelabros, guantes y muchos otros objetos cuyas formas tienen un evidente interés histórico para el medievalista.

Parece ser que el origen de las marcas de agua hay que buscarlo en la Italia del siglo XIII; esa innovación técnica, verdadera marca de fábrica impresa en la hoja en el momento de su fabricación, habría asegurado durante los sigios siguientes un puesto escogido al papel italiano en el mercado de los países de la Europa Occidental (2). El proceso de elaboración mediante el cual se obtienen las filigranas es muy sencillo y ha sido descrito por diversos autores, pero conviene recordario (3): la madera descortezada es reducida a fibras y cocida a presión en una caldera; luego, se combina con colas y se diluye para obtener la pasta de papel que, tras ser blanqueada y refinada, se mezcla en una tina donde finaliza la primera fase de su fabricación. 
De esa tina toma el operario la cantidad de pasta necesaria para hacer una hoja y la deposita en la forma o molde, un recipiente rectangular con fondo de tela metálica. El agua contenida en la pasta es eliminada por escurrido a través de dicha tela metálica, al mismo tiempo que las fibras exprimidas se entrecruzan longitudinal y transversalmente. Si esa tela metálica lleva un dibujo de alambre en relieve, que hace más delgado el papel por la zona que entra en contacto con la pasta, el mismo es luego visible al trasluz. Éste es el origen de la filigrana o marca de agua, a partir de una técnica que apenas ha cambiado desde su invención en el siglo XIII hasta nuestros días. Hay que destacar, como lo hace Sánchez Real, que ese método impide la existencia de dos formas (o alambres) de hacer filigranas idénticos - puesto que cada una, hecha manual e independientemente, daba marcas distintas-, de manera que dos filigranas iguales responden a la misma forma y han salido del mismo taller y bandeja con un intervalo de tiempo relativamente breve, por más que aparezcan en papeles muy alejdos entre sí geográficamente (4).

Si los italianos fueron los inventores de la marca de agua, es lógico suponer la trascendencia que sus modelos habrían tenido en la Europa bajomedieval. Jean Irigoin ha estudiado la introducción del papel italiano en España a partir del siglo XIII (5), y otros muchos autores han puesto el acento sobre el origen italiano de muchas de las filigranas $-y$, aparentemente por tanto, de los papeles en que se encuentran - halladas en documentos hispanos; según Josepa Cortes, la mayoría de las filigranas recogidas en el archivo de Sueca denotan ese origen (6); Bofarull y Sans defendía la procedencia italiana de todos los papeles con filigranas de animales (7); y Briquet, en su ya clásico y amplio estudio sobre filigranas procedentes fundamentalmente de archivos italianos y franceses, atribuye también un origen italiano a las figuras de anclas, anillos, carros, tijeras, flores con forma de tulipa y letras, todas las cuales resultan enormemente frecuentes en los documentos españoles (8).

¿Quiere esto decir que el papel empleado en Aragón y Castilla durante los siglos XV y XVI era importado, al menos en una buena parte, de Italia? Es muy posible que fuera así, pero también es evidente la existencia de industrias papeleras en Játiva y otros lugares peninsulares; $y$, por supuesto, no hay que perder de vista que artesanos locales, especialmente los levantinos, pudieron haber imitado esas marcas a partir de modelos italianos que ellos mismos habrian implantado y, en su caso, modificado para la realización de su propio papel. Por eso, y por la falta de estudios en profundidad, es tan difícil poder establecer con garantías el origen de cada filigrana y de su respectivo soporte. 
Al problema del origen se une el del significado de las marcas que, hoy por hoy, no está suficientemente clarificado. Es evidente que se trata de una marca de origen, tanto más en casos como el de las manos 123 y 124 de nuestra recopilación -muy parecidas entre sí y perfectamente diferenciadas del resto- y los jarrones 78 a 80 , procedentes todos ellos de documentos fechados en Bruselas en los primeros años del siglo XVI. Pero ¿qué significan la variedad de dibujos existentes? ¿Denotan su origen en una ciudad, en una región o en un taller concreto? Es difícil decirlo. Por nuestra parte, consideramos que, en efecto, esas filigranas tienen que ver con las marcas que durante la Baja Edad Media llevan los diferentes productos artesanales elaborados en cada lugar, a través de las cuales puede comprobarse la calidad de los mismos, su ciudad de procedencia y, en muchos casos, el taller o maestro ejecutor. Sin embargo, además de la variedad en las figuras, deseariamos llamar la atención sobre esas letras que aparecen en muchas de ellas y que autores como Briquet han considerado las iniciales del papelero que las hizo, letras que se repiten una y otra vez por todas partes: BF (figs. 50, 53, 195, 196), $F B(19,24,153,191), F M(40,155), \operatorname{BRP}(54,203)$ y otras similares aparecen en manos y figuras y nos hacen preguntarnos si no se podria pensar que, más que la misma forma de aquéllas, son esas letras o signos realizados junto a las mismas las que marcan el rasgo distintivo de cada tipo de papel. Quizá la repetición de unas mismas iniciales en dibujos distintos signifique el origen común de dos papeles con filigrana diferente, pero salidos del mismo taller.

Todo ello está aún por determinar con exactitud y, de momento, lo único realmente cierto es la coincidencia cronológica de las formas en un espacio de unos veinte años, pasado el cual desaparecen. Eso queda explicado por la idea de Sánchez Real antes citada (a dos filigranas idénticas corresponde una misma bandeja de fabricación) y también porque posiblemente las formas se gastaban, pasaban de moda, y eran sustituidas por otras (incluso en el mismo taller) en plazos de tiempo más o menos breves.

$Y$ asi resulta que las formas que aparecen en Córdoba y que hemos encontrado repetidas en otros lugares se insertan siempre en documentos de la misma época, cuando no exactamente del mismo año. Así, la mano230, de 1492, aparece en Palermo en 1487 y en Castellón (1491-93) y Mosqueruela (1493); el carro 32 (1449) aparece en papeles del archivo de Mosqueruela fechados en 1450, y el 35 (1460), en Villarreal (1465), Mosqueruela (1460) y Játiva (1453). Quizá el caso más notable de coincidencia (y repetición de un tipo de papel usado, por tanto, en todos esos lugares) sea el de la flor 
en forma de tulipa número 63 (1514), que se encuentra también en Castellón (1474), Villarreal (1491), Sueca (1493), Játiva (1494) y Zaragoza (1518), lo que evidencia la gran difusión de ese papel, tanto desde el punto de vista geográfico, como de su prolongación entre los años 1470 y 1520 . Otros casos similares pueden encontrarse en el anexo 3.

A través de ese cuadro y, simplemente, echando una ojeada a los diversos trabajos publicados sobre el tema, se llega fácilmente a la siguiente conclusión: que los mismos tipos de figuras aparecen en todas partes. Para su adecuado estudio, Sánchez Real propuso una división en tres categorías de formas: la familia, tema o motivo sobre el que versa la filigrana; el tipo, que vendría dado por las diferentes maneras de presentar el tema; y las variantes o variaciones producidas en cada uno de los tipos señalados (9). Las familias, como queda dicho, son comunes a todos los papeles de la época conservados en los archivos españoles y destacan entre ellas las manos, carros, montes, animales, letras, tijeras, anillos, cruces, flores y rostros humanos como las más corrientes, cada una de las cuales incluye en su interior un gran número de variantes.

Pero aunque en todos los archivos existen los mismos modelos, en Córdoba destaca de manera especial el motivo de la mano, que se repite con mayor cantidad de variantes que en cualquier otro fondo documental estudiado. Ello obedece, sin duda, al posible origen del papel empleado en Córdoba, importado de talleres que necesariamente usarian esa filigrana como tema principal (dado que en Córdoba no parece haber existido durante los años a que se refiere nuestro estudio, ningún centro de elaboración de papel $o$, si así fue, no nos ha quedado constancia alguna de ello, ni entre los documentos municipales ni entre las escrituras notariales). Pero también se explica por el marco cronológico que hemos asignado a nuestro estudio, puesto que es a partir de la primera mitad del siglo XVI cuando el predominio de la mano entre las familias de filigranas se hace más evidente y así, mientras que para el período $1450-1500$ sólo 37 de las 88 figuras recogidas son manos (habria así un 42 por 100 de manos sobre un 58 por 100 de otros dibujos), para el de 1500-1550 el número de éstas asciende a 147 sobre 206 (es decir, el porcentaje se ha elevado hasta el 71 por 100 de manos y sólo el 29 por 100 de filigranas con otras figuras). Todo ello demuestra que las filigranas estuvieron sometidas en la época a una rápida evolución que sería importante poder determinar para tener un mejor conocimiento de las mismas. El ya citado es uno de sus principales rasgos, al menos tal y como se manifiestan en Córdoba, y otro podría ser la progresiva sustitución de los dibujos simples, de trazos sencillos e irregulares, que aparecen en los docu- 
mentos más antiguos (carros, montes, círculos, animales), por los más complicados y artísticos de los papeles más modernos (anillos, jarrones, escudos, pájaros), que llegarán en el siglo XVIII a hacer de las filigranas auténticas maravillas.

Para concluir esta pequeña introducción sobre las filigranas del Archivo Municipal de Córdoba queremos indicar que hemos examinado toda la documentación conservada en el mismo y datada entre los años 1450 y 1550; la mayoría de los documentos se encuentran en legajos sueltos, a los que hay que añadir los libros de Ordenanzas, los de Actas Capitulares y los de Sentencias de Términos, en general más monótonos, porque a lo largo de todas sus páginas suele aparecer el mismo tipo de dibujo. El motivo de escoger esas dos fechas como marco cronológico ha sido la práctica inexistencia de documentación anterior al siglo XV en este archivo, lo que nos ha obligado a llegar en nuestro estudio hasta la mitad del siglo XVI a fin de poder examinar en conjunto las filigranas cordobesas de la época pues, como destaca Sánchez Real, la importancia de una filigrana no está sólo en ella, sino en la relación que tenga con las otras que forman el fondo que se estudia (10). Por lo tanto, habia que disponer de un número suficiente de estas figuras.

La técnica seguida para su recogida fue muy sencilla: sobre dos soportes laterales apoyamos un cristal opaco y bajo éste, enmedio de ambos soportes, un flexo de luz blanca que incidía directamente sobre la cara inferior del cristal y formaba así un foco de luz difusa muy apropiado para observar el trasluz del papel. Sobre éste, copiamos la figura a lápiz, sobre papel cebolla, y luego la trasladamos a tinta sobre papel vegetal. Ocasionalmente, usamos plásticos traslúcidos azules o verdes por si contribuían a definir los perfiles de la figura, pero en general llegamos a la conclusión de que eran poco útiles y resultaba mejor el copiado directo sobre el papel original. Las figuras están reproducidas a tamaño natural y agrupadas por orden alfabético. A cada una asignamos un número ordinal con el que señalamos el año de la fecha del documento del que fueron recogidas (anexo 1); la sección y serie del archivo en que se encuentran (anexo 2); y aquéllas que hemos encontrado repetidas en los papeles de otros archivos estudiados (anexo 3). Para éste último fin, hemos realizado un cuadro inspirado en el propuesto por Ariño Rico (11), a la izquierda del cual indicamos el tipo de figura encontrada en Córdoba, el número ordinal asignado y el año en que aparece; y a la derecha, la localidad y fecha en que aparece una figura equivalente, así como el autor del artículo que la recoge y el número que en él se le asigna. La principal conclusión que se obtiene del mismo es la ya señalada de coincidencia cronológica entre formas iguales. 
Completa el presente estudio una pequeña relación bibliográfica, útil para quien desee enfrentarse con el sugestivo tema de las filigranas y, por supuesto, la reproducción fiel de las conservadas en el Archivo Municipal de Córdoba, dibujos que son los auténticos protagonistas de este trabajo. 
(1) SÁNCHEZ REAL, J. «Las filigranas del papel», Ligarzas, 4 (1972), p. 264.

(2) IRIGOIN, J. «La datation par les filigranes du papier», Codicologica. Les materiaux du livre manuscrit, 5 (1980), p. 9.

(3) SÁNCHEZ REAL, J. Op. cit., pp. 261-262; GERARDY, M. Th., «Les techniques d'examen des filigranes", Les techniques de laboratoire dans l'etude des manuscrits, París, 1974, pp. 143-157; MADURELL MARIMON, J. M., El paper a les terres catalanes. Contribució a la seua historia, Barcelona 1972.

(4) SÁNCHEZ REAL, J. «Criterios a seguir en la recogida de filigranas», Ligarzas, 6 (1974), p. 362

(5) IRIGOIN, J., «L'introduction du papier italien en Espagne», Papiergeschichte, 10 (1960), pp. 29-32.

(6) CORTÉS, J., «Filigranes medieval de l'Arxiu Municipal de Sueca 1399-1500», Quaderns de Sueca, 5 (1984), p. 10.

(7) BOFARULL Y SANS, F., Los animales en las marcas del papel, Vilanova y Geltrú, 1910.

(8) BRIQUET, Ch., Les filigranes, Amsterdam, 1968, 4 vols.

(9) SÁNCHEZ REAL, J., «Criterios a seguir...», p. 365.

(10) SÁNCHEZ REAL, J., «Las filigranas del papel...", p. 263.

(11) ARIÑO RICO, L. «Filigranas de Mosqueruela», Ligarzas, 6 (1974), p. 122

\section{BIBLIOGRAFÍA}

ABELLÁN PÉREZ, J., "Las filigranas medievales del Archivo Municipal de Murcia 1399-1455», Miscelánea Medieval Murciana, 6 (1980), 135-146.

ARIÑO RICO, L., «Filigranas de Mosqueruela», Ligarzas, 6 (1974), 121-360.

BOFARULL Y SANS, F., «La heráldica en las filigranas de papel», Memorias de la Real Academia de Buenas Letras, VII, Barcelona, 1901. págs. 485-556.

BOFARULL Y SANS, F., Los animales en las marcas de papel, Vilanova y Geltrú, 1910.

BRIQUET, Ch., Les filigranes. Dictionaire historique des marques du papier de leur apparition vers 1282 jusq'en 1600. 3 vols. Leipzig, 1923, reimpresión New York, 1977.

CABANES, M. L., CARCEL, M. y YAGO, M. C., «El Archivo de la Colegiata de Játiva y sus filigranas», Ligarzas, 6 (1974).

CORTÉS, J., «Filigranes medievals de l'Arxiu Municipal de Sueca 1399-1500», Quaderns de Sueca, 5 (1984), 9-48.

DOÑATE SEBASTIÁ, J., «Filigranas del Archivo Municipal de Villarreal», Ligarzas, 5 (1973), 111-244. 
EINEDER, G., The ancient Paper Mills of the former Austro-Hungarian Empire and their Watermarks. 1962.

FISKAA, H. M. y NORDSTRAND, O. K., Paper and Watermarks in Norway and Denmark. 1978.

GAYOSO, G., «Antigua nomenclatura papelera española», Investigación y técnica del papel, 10 (1973).

GERARDY, M. Th., “Les techniques d'examen des filigranes», Les techniques de laboratoire dans l'etude des manuscrits, París, 1974, 143-157.

IRIGOIN, J., «La datation par les filigranes du papier», Codicologica. Les materiaux du livre manuscrit, 5 (1980), 9-36.

IRIGOIN, J., «La datation des papiers italiens des XIII' et XIV ${ }^{\circ}$ siècles", Papiergeschichte, 18 (1968), 49-52 y 76.

IRIGOIN, J., «L'introduction du papier italien en Espagne», Papiergeschichte, 10 (1960), 29-32.

IRIGOIN, J., «Les filigranes de Fabriano (noms de papetiers) dans les manuscrits grecs du debut du XIV० siècle», Scriptorium, 12 (1958), 44-50 y 281-82.

LINDT, J., The Paper Mills of Berne and their Watermarks (1465-1859), Hilversum, 1964.

LÓPEZ, J. y Martín, M. J., «Filigranas del Archivo Municipal de Castellón de la Plana (Manual del Consells)», Ligarzas, 5 (1973), 7-110.

MADURELL MARIMÓN, J. M., El paper a les terres catalanes. Contribució a la seua história. Barcelona, 1972.

MOSIN, V., Anchor Watermarks. 1973.

MOSIN, V. y TRALJIC, S. M., Filigranes des XII/0 et XIV siècles. Zagreb, 1957. 2 vols.

RIDOLFI, R., Le filigrane di paleotipi. Firenze, 1957.

SÁNCHEZ REAL, J., Las filigranas de animales en los archivos de Tarragona. Tarragona, 1959.

SÁNCHEZ REAL, J., «Las filigranas del papel», Ligarzas, 4 (1972), 259-266.

SÁNCHEZ REAL, J., «Criterios a seguir en la recogida de filigranas», Ligarzas, 6(1974), 361-371.

SÁNCHEZ REAL, J., El papel y sus filigranas en los incunables tarraconenses. Tarragona, 1980.

STEVENSON,A., “Watermarks are twins", Studies in Bibliography, 4 (1952), 57-91.

VALLS SUBIRA, O., El papel y sus filigranas en Cataluña, Amsterdam, 1970. 


\section{ANEXO II SIGNATURA DE LOS DOCUMENTOS}

El primer número indica la figura expresada; los dos siguientes, la Sección y la Serie del Archivo Municipal en que se encuentra el documento que la contiene.

\begin{tabular}{|c|c|c|c|}
\hline 1. $2-30$ & 24. $7-7$. & 47. $1-15$ & 70. 6-7. \\
\hline 2. $7-7$. & 25. $1-11$ & 48. $12-2$ & 71. 2-1. \\
\hline 3. $12-2$ & 26. LAC 1479. & 49. 6-1. & 72. $2-27$ \\
\hline 4. $2-30$ & 27. $1-2$ & 50. $2-12$ & 73. $7 \cdot 7$ \\
\hline 5. $12-1$ & 28. $5-67$. & 51. $2-1$ & 74. 1-11. \\
\hline 6. LAC 1479 (1). & 29. LAC 1493. & 52. 2.1. & 75. 16-1. \\
\hline 7. $2-30$ & 30. $6 \cdot 1$ & 53. $3-18$ & 76. $2-8$ \\
\hline 8. $2-14$ & 31. $2-2$ & 54. $6 \cdot 6$ & 77. $1-11$. \\
\hline 9. $2-1$. & 32. $2-20$. & 55. $2-2$ & 78. $1-1$ \\
\hline 10. $2-30$ & 33. $5-67$. & 56. $13-1$ & 79. $5-5$. \\
\hline 11. $1-6$. & 34. 6-7. & 57. $12-1$. & 80. $6-28$ \\
\hline 12. LAC 1496. & 35. $6-42$ & 58. LAC 1507. & 81. 2-1. \\
\hline 13. $6-1$ & 36. 2.8 & 59. $2-8$ & 82. $6-42$ \\
\hline 14. $7-7$. & 37. $18-2$ & 60. $2-20$ & 83. 6-1. \\
\hline 15. $2-30$ & 38. $6-42$. & 61. 1-2. & 84. 12-2. \\
\hline 16. 6-7. & 39. 1-6. & 62. $2-30$ & 85. 3-3. \\
\hline 17. $2-17$ & 40. LAC 1513. & 63. $2-30$ & 86. $1-10$ \\
\hline 18. 5-69. & 41. LAC 1514. & $64.6-42$ & 87. $12-3$ \\
\hline 19. $12-1$ & 42. $2 \cdot 2$ & $65.3-6$ & 88. $12-1$ \\
\hline 20. $6-20$ & 43. $2-1$ & $66.12-1$ & 89. 2-30. \\
\hline 21. $12-1$. & 44. $2-12$ & 67. 6-31. & 90. $2-1$ \\
\hline 22. 3-18. & 45. $2-1$ & $68.1-2$ & $91.12-2$ \\
\hline 23. $6-1$. & 46. 6-36. & 69. LAC 1479. & 92. $1-10$ \\
\hline
\end{tabular}




\begin{tabular}{|c|c|c|c|}
\hline 93. 1-2. & 133. 6-1. & 173. $12-3$ & 213. $1-5$ \\
\hline $94.1-6$ & 134. 6-7. & 174. $12-1$ & 214. 2-21. \\
\hline $95.1-2$ & 135. $2-30$ & 175. $1-6$ & $215.1-4$ \\
\hline 96. 2-1. & 136. $5-42$ & 176. $1-11$ & 216. 12-7. \\
\hline 97. 6-44. & 137. $1-6$ & 177. $2-1$ & 217. 6-1. \\
\hline $98.1-2$ & 138. $2-6$ & 178. $6-21$ & 218. 5-67. \\
\hline 99. 5-21. & 139. 12-1. & 179. $2-17$ & $219.7-7$ \\
\hline 100. 6-1. & 140. $12-2$ & 180. $5-40$ & 220. $6-1$ \\
\hline 101. 12-1. & 141. 1-10. & 181. $5-40$ & 221. $7-7$. \\
\hline 102. 2-20. & 142. 1-6. & 182. $5-40$. & 222. 1-11. \\
\hline 103. $1-2$ & $143.6-1$ & 183. $1-6$ & 223. 7-7. \\
\hline 104. $1-2$ & 144. 12-3. & $184.12-1$ & 224. $12-1$. \\
\hline 105. $1-2$ & 145. 6-1. & 185. 6-21. & 225. $6-6$ \\
\hline $106.2-2$ & 146. $2-1$ & 186. $2-1$ & 226. 12-3. \\
\hline 107. $1-2$ & 147. $12-1$ & 187. $2 \cdot 12$ & 227. $1-15$ \\
\hline 108. 1-4. & 148. $1-6$ & 188. 6-29. & 228. 3-7. \\
\hline 109. $12-1$. & 149. 6-13. & 189. 12-1. & 229. $12-2$ \\
\hline 110. $2-1$ & 150. $6-36$ & 190. $6-1$ & 230. $12-2$ \\
\hline 111. $\dagger-17$ & 151. $5-50$ & 191. $2-1$ & 231. 6-1. \\
\hline 112. 1-15. & 152. $12-1$ & 192. 12-3. & 232. 1-11. \\
\hline 113. $1-15$ & 153. $1-5$. & 193. LAC 1507. & 233. 1-7. \\
\hline 114. $1-11$. & 154. $2-30$ & 194. 3-18. & 234. $1-6$. \\
\hline 115. $1-2$ & 155. 6-1. & 195. 5-67. & 235. $2-1$ \\
\hline 116. 2-6. & 156. $6-1$ & 196. $6-7$ & 236. LAC 1503. \\
\hline 117. $12-1$. & 157. $6-37$ & 197. 6-13. & 237. $12-7$ \\
\hline 118. 1-10. & 158. $12-1$ & 198. $2-30$ & $238.6-1$ \\
\hline 119. 3-6. & 159. $6-1$ & 199. 2.30. & 239. 2-30. \\
\hline 120. 6-15. & 160. $12-4$ & 200. $3-6$ & 240. $1-6$ \\
\hline 121. $9 \cdot 1$ & 161. $12 \cdot 1$ & 201. 6-29. & 241. 1-11. \\
\hline 122. 6-7. & 162. $6-1$ & 202. 6-7. & 242. 1-11. \\
\hline $123.1-4$ & 163. 2-13. & 203. 6-1. & 243. LAC 1498. \\
\hline 124. $1-7$ & 164. $12-2$ & 204. 12-1. & 244. LAC 1498. \\
\hline 125. $6-2$ & $165.6-1$ & $205.2-4$ & 245. 6-1. \\
\hline $126.2-4$ & 166. 1-11. & 206. 6-2. & 246. $7 \cdot 7$. \\
\hline 127. $1-11$. & 167. $1-6$ & 207. 6-1. & 247. 7-7. \\
\hline 128. $1-11$ & 168. 3-18. & 208. $6-2$ & 248. $12-1$ \\
\hline 129. $1-11$. & 169. $1-8$ & $209.12-3$ & 249. 1-11. \\
\hline 130. $2 \cdot 8$ & 170. $3-6$ & $210.6-1$ & $250.2-2$ \\
\hline 131. $2 \cdot 30$ & 171. $2-2$ & 211. 1-6. & 251. $2-1$ \\
\hline 132. $6-29$ & 172. $1-11$ & 212. 6-7. & 252. 1-12. \\
\hline
\end{tabular}


253. 13-1.

254. 7-7.

255. 2-21.

256. 6-9.

257. 16-1.

258. 16-7.

259. 3-6.

260. 1-15.

261. 13-1.

262. $12-1$.

263. 4-2.

\section{(1) Contenido}

286. $2-30$.

287. 12-3.

288. $1-2$.

289. 5-32.

290. 5-12.

291. 12-1.

292. 12-1.

293. 5-12.

294. 1-2.
275. 2-1.

276. $1-10$.

277. $2-1$.

278. 12-2.

279. 1-11.

280. 1-7.

281. $1-7$.

282. 4-2.

283. 6-42.

284. $1-2$.

285. 1-2.
285. $1-2$.

$\begin{array}{ll}\text { 264. } 6-7 . & 275.2-1 . \\ 265.1-2 . & 276.1-10 \\ 266.12-1 . & 277.2-1 . \\ 267.2-8 . & 278.12-2 \\ 268.1-11 . & 279.1-11 \\ \text { 269. } 12-1 . & 280.1-7 . \\ \text { 270. } 6-29 . & 281.1-7 . \\ \text { 271. } 1-11 . & 282.4-2 . \\ \text { 272. LAC } 1496 . & 283.6-42 \\ \text { 273. 2-8. } & 284.1-2 . \\ \text { 274. } 2-6 . & 285.1-2 .\end{array}$

do en el Lib
273. $2-8$.

274. 2-6. del añ 


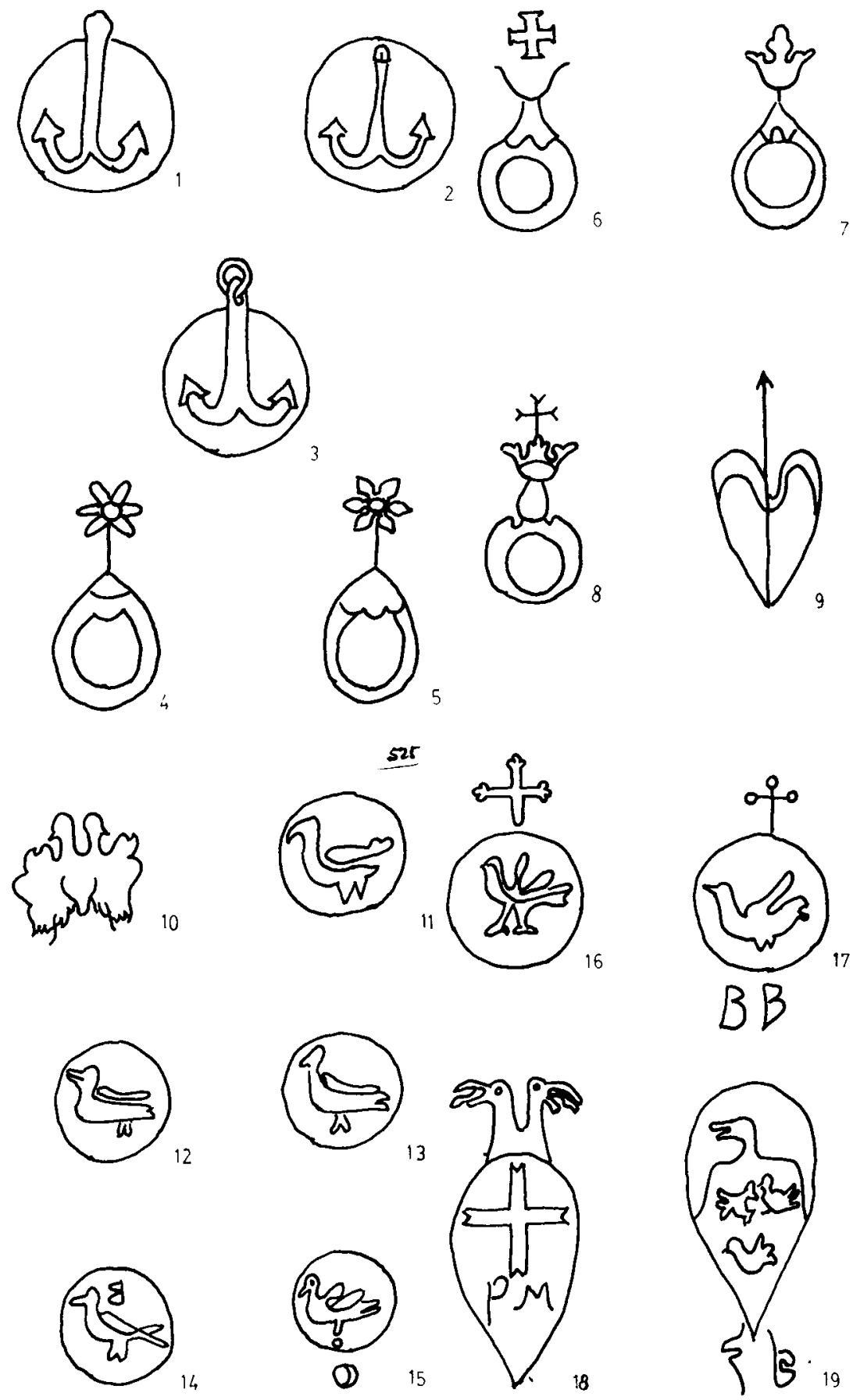


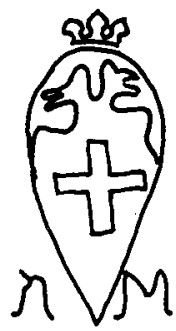

20
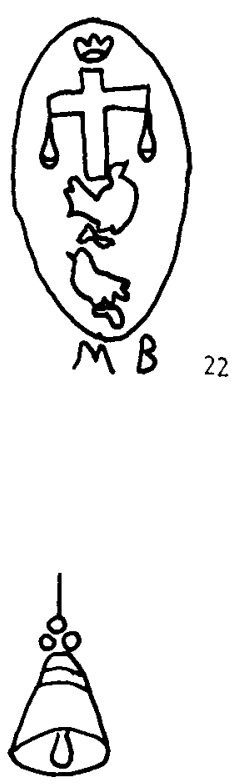

28

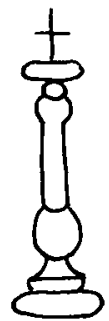

30

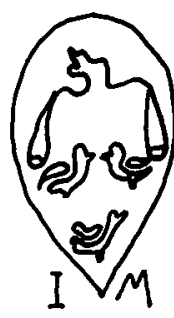

21
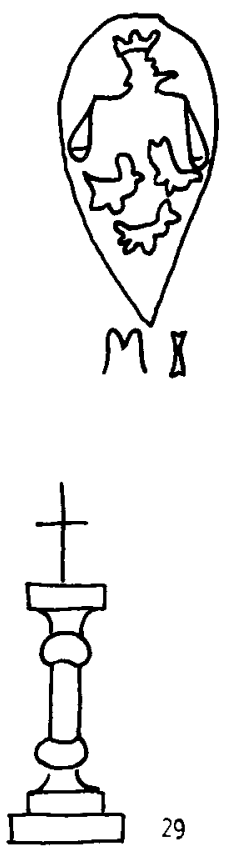

29

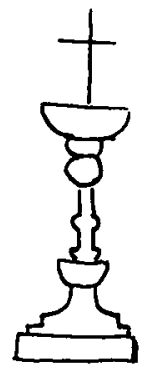

31

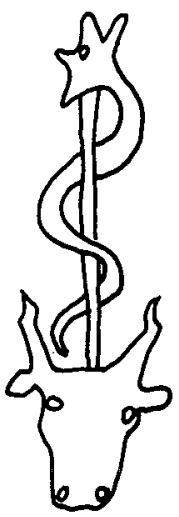

25
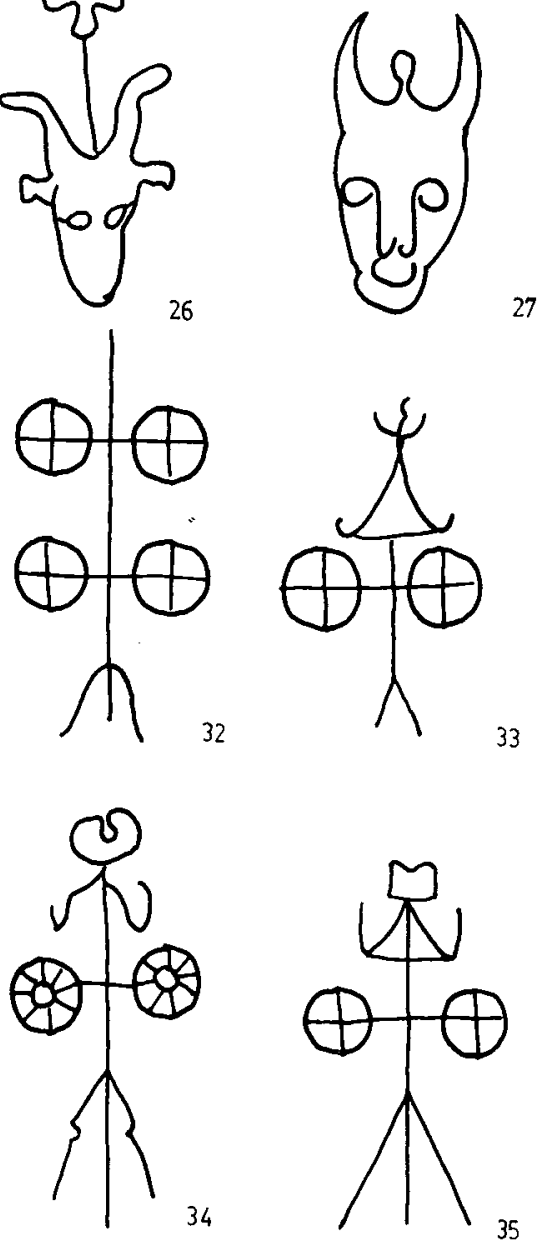

420 

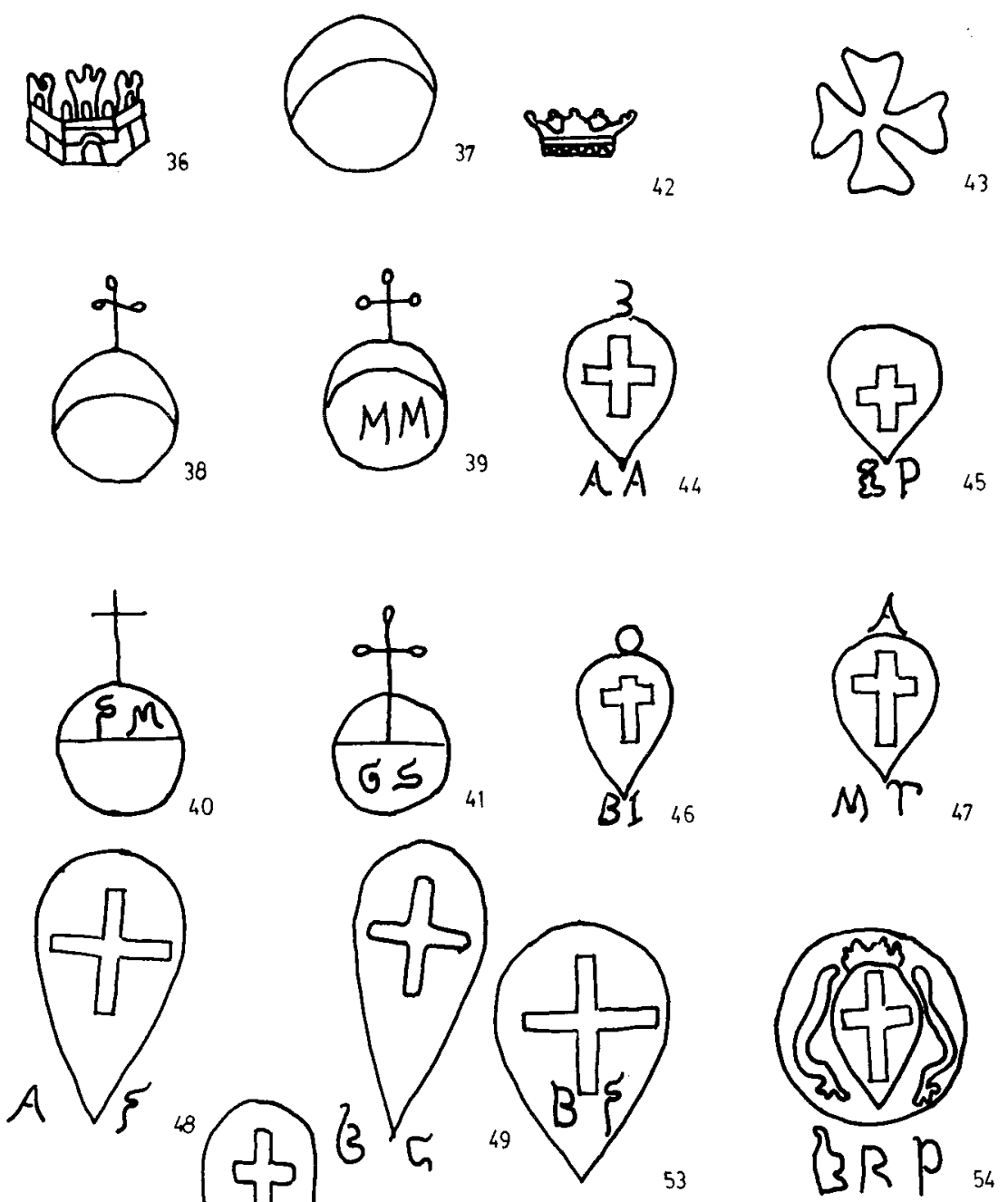

53
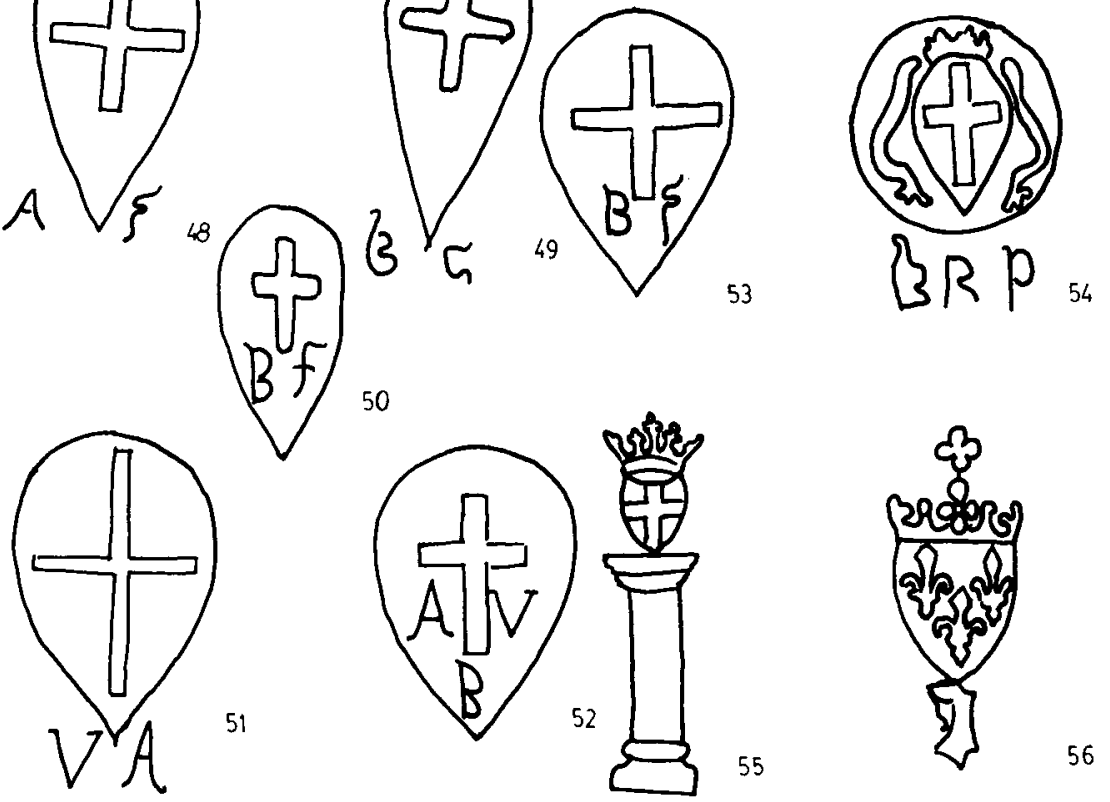
م్య

57

๙ิน

58
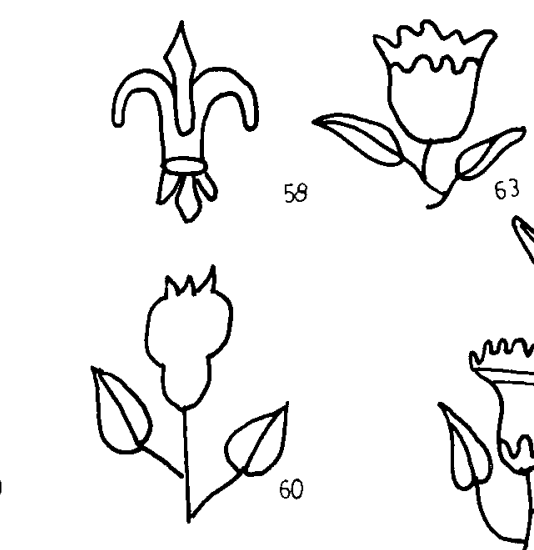

59
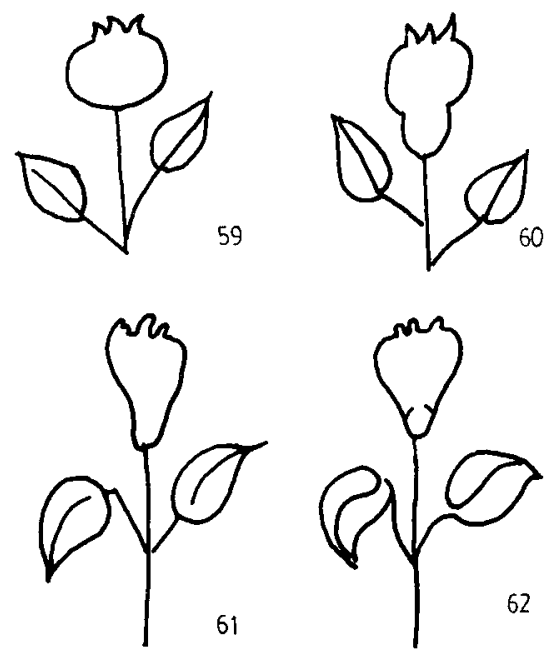

66
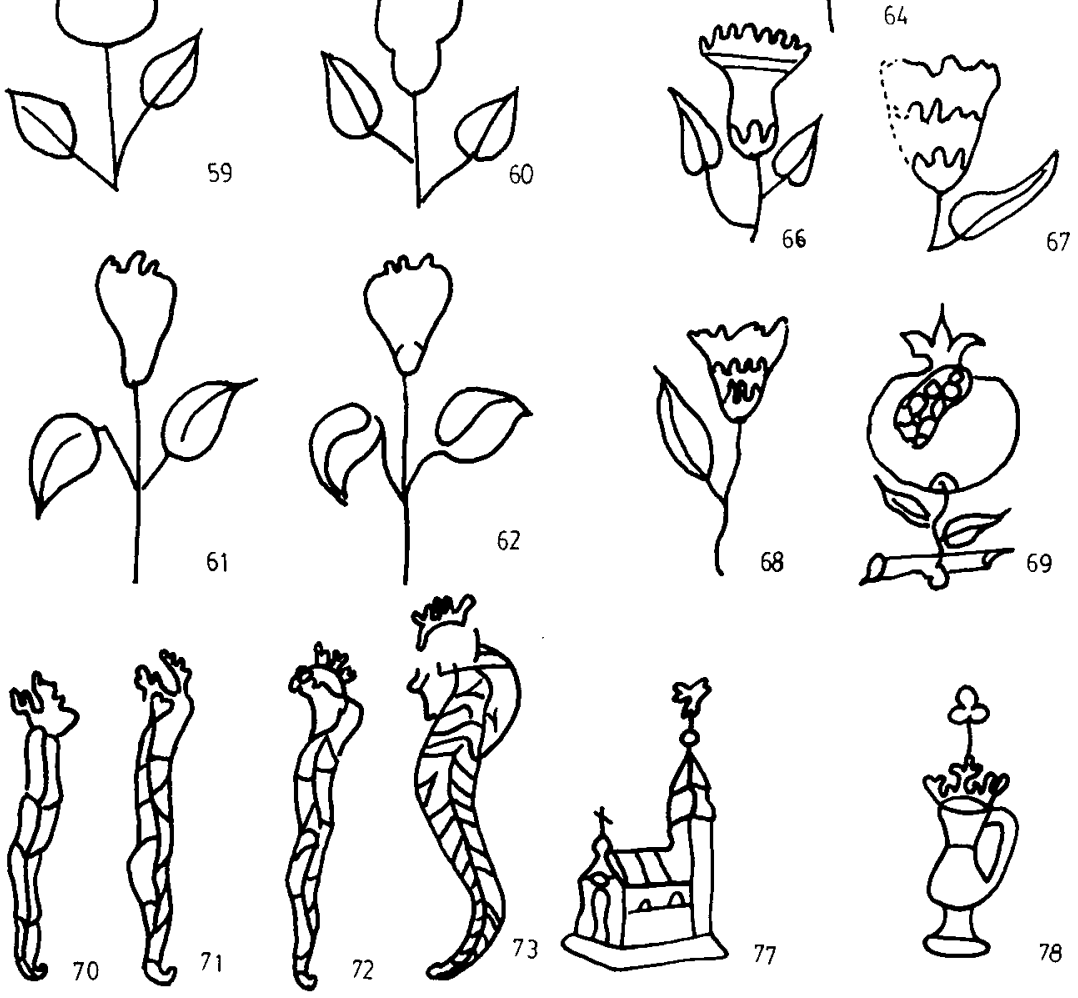

68

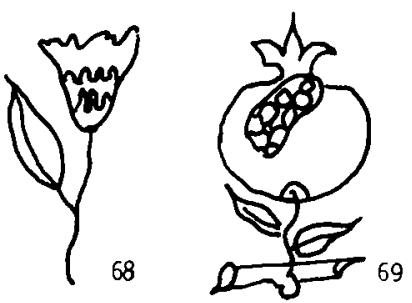

65

7
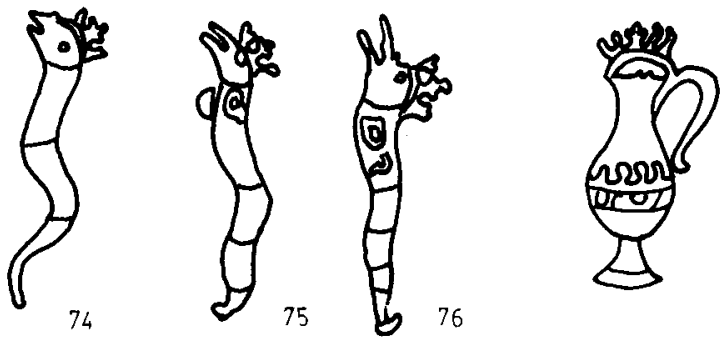

77

78

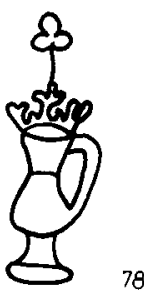

422 


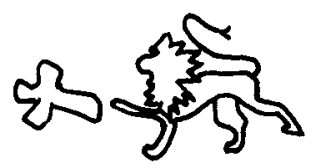
81

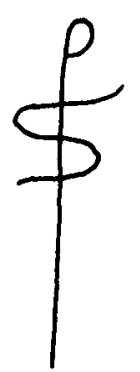

82

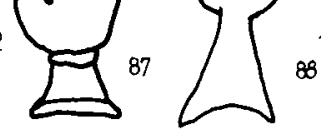

$\mathbb{S}_{83} P t_{84}$

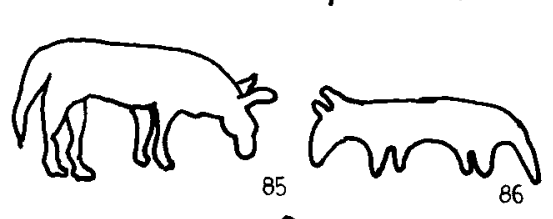
sp

$\infty$

(in)

sक<smiles>C1CCCCC1</smiles>

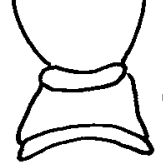

94

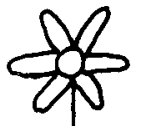

यू की

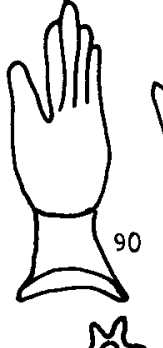

影 路

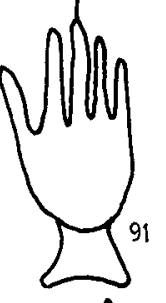

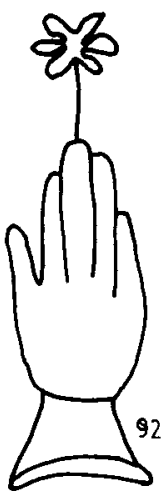

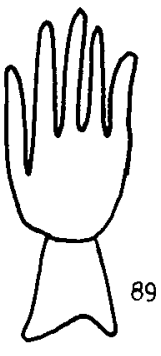

89 

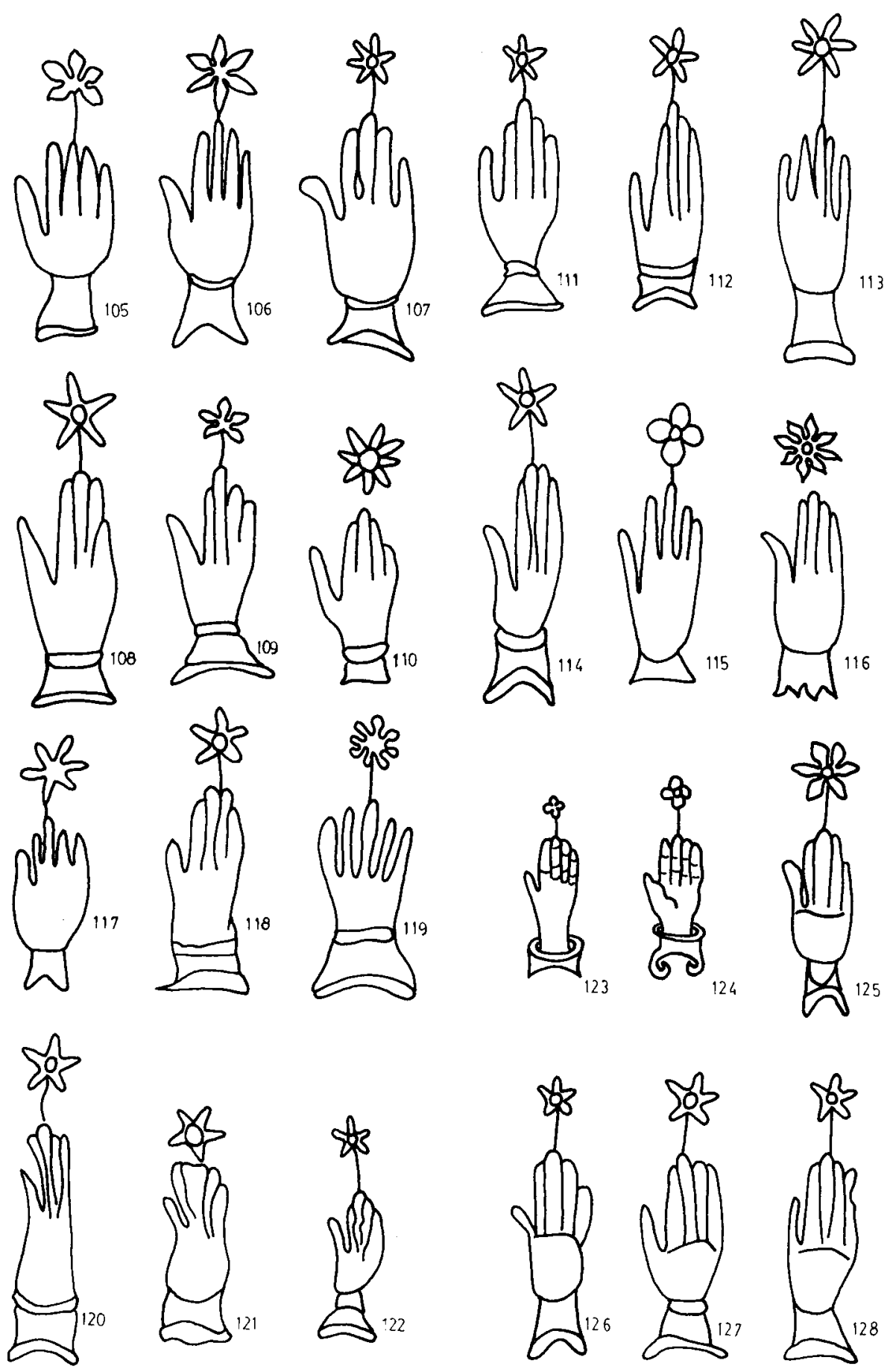

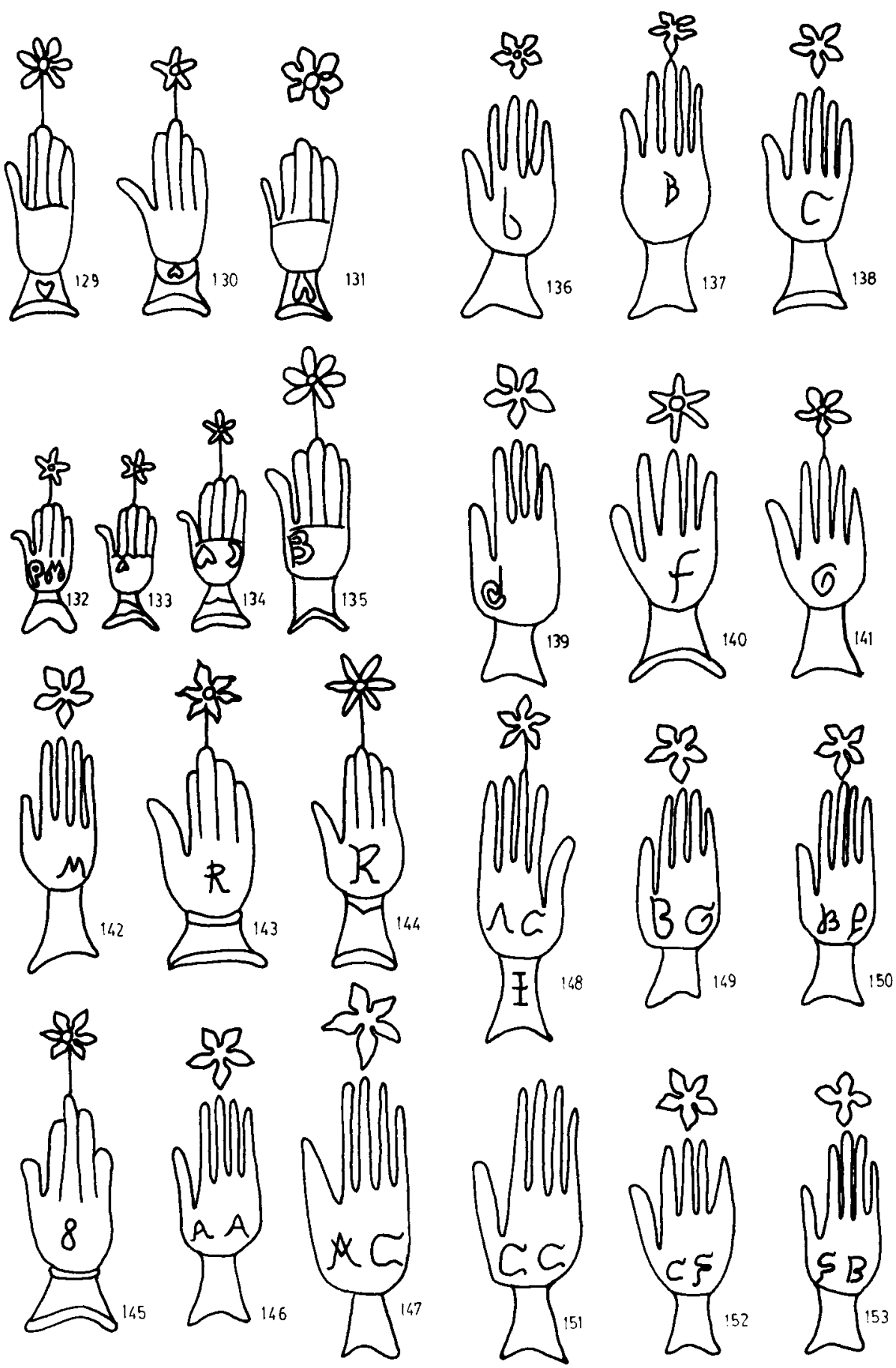

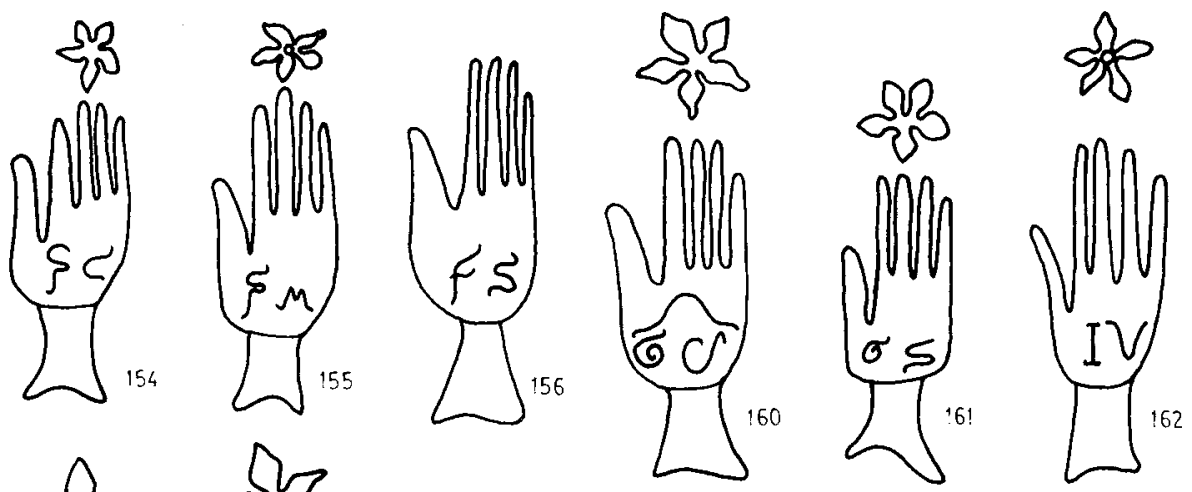

w क्रा है
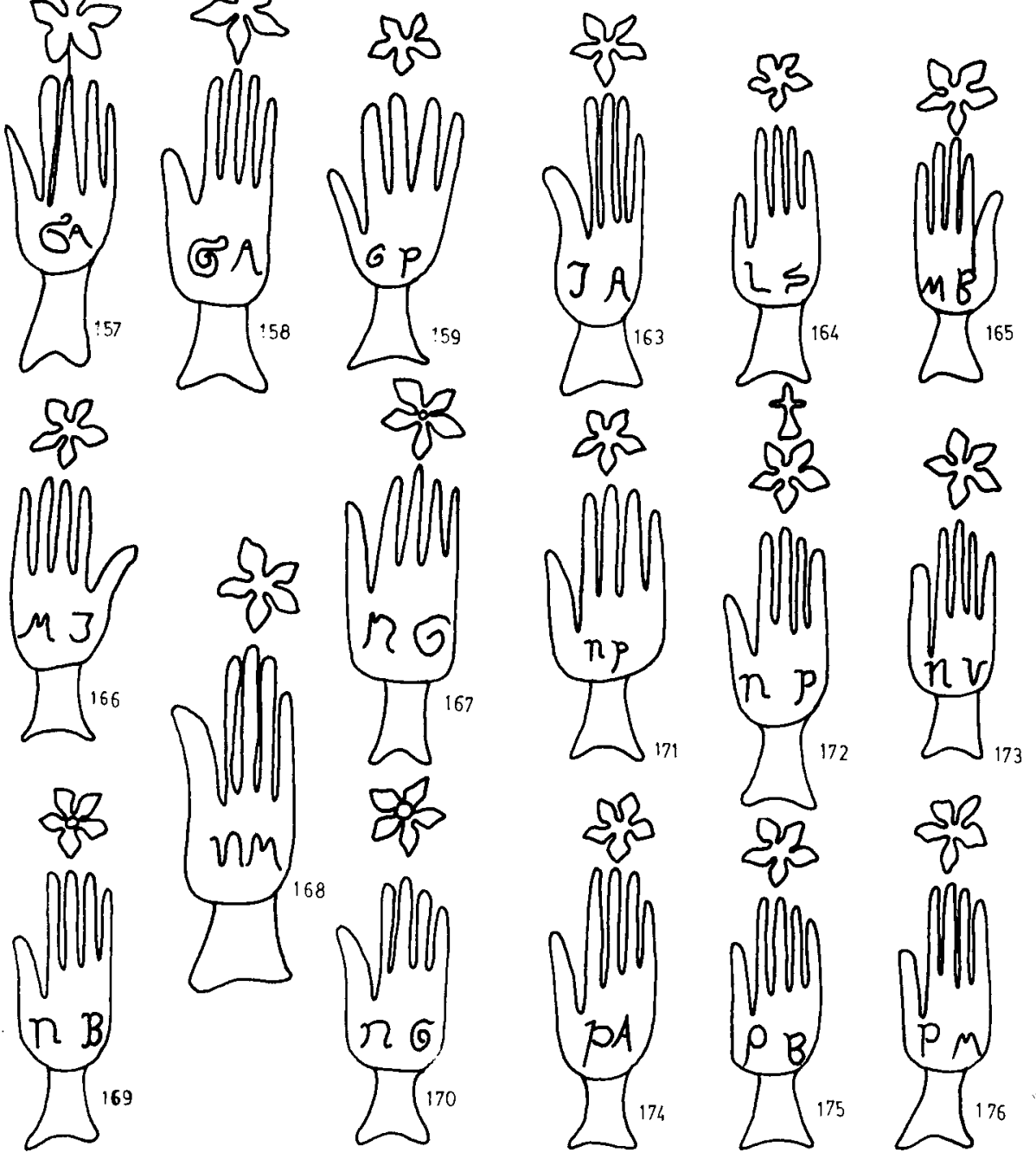

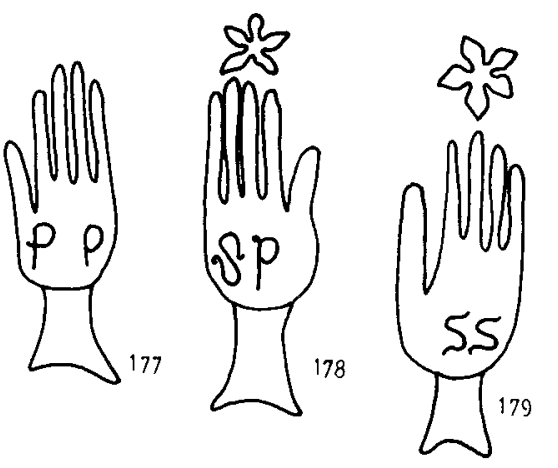

is

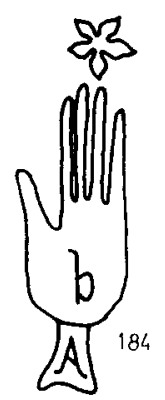

\&s
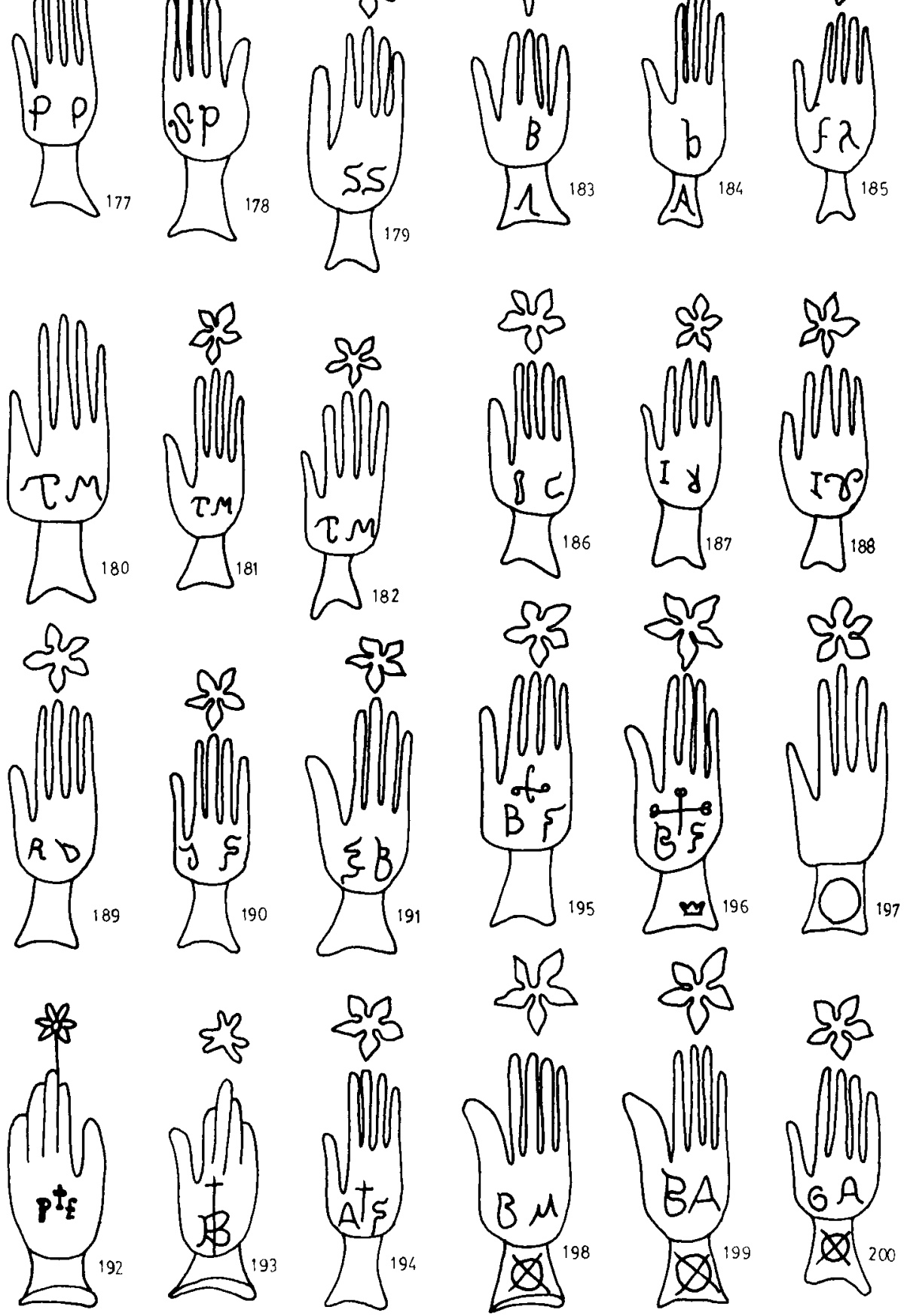


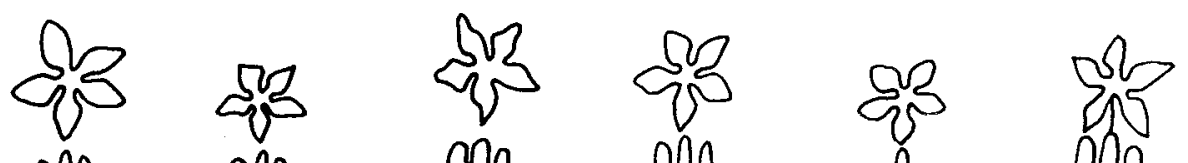
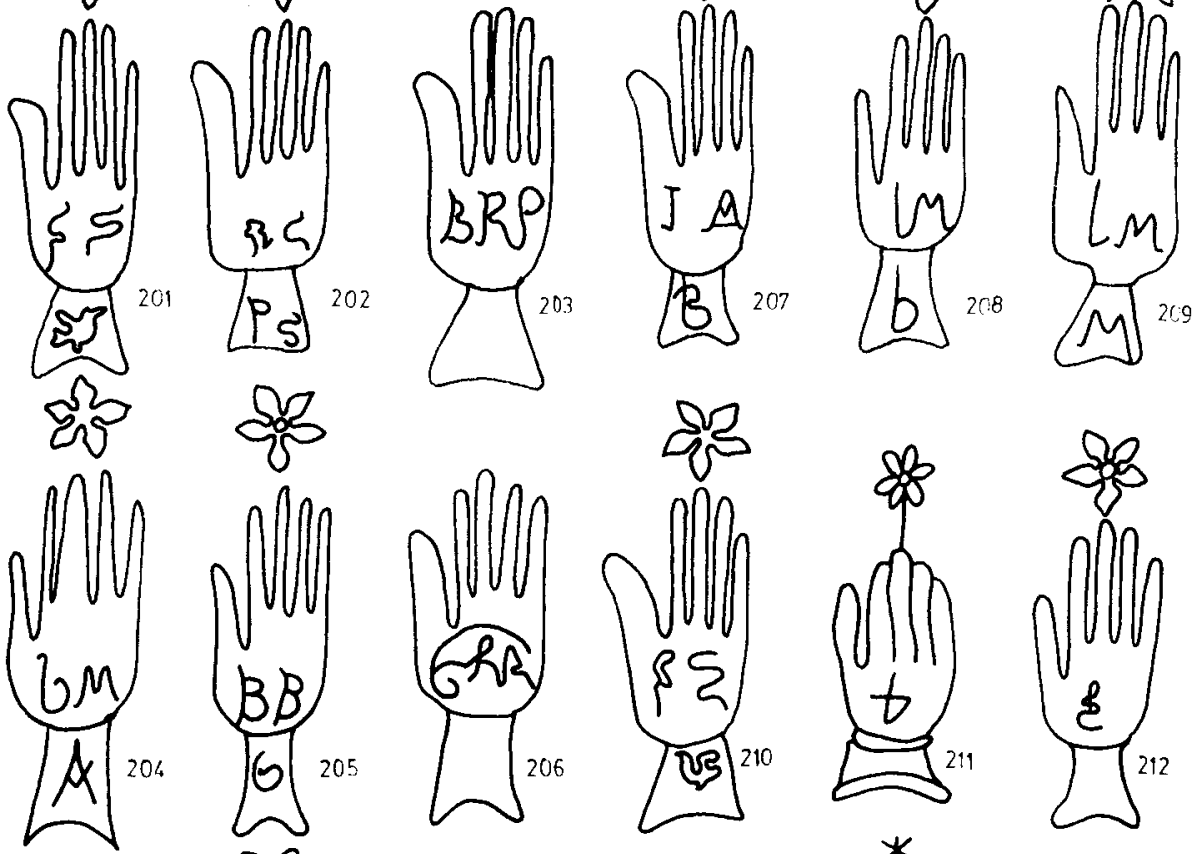

32

s?
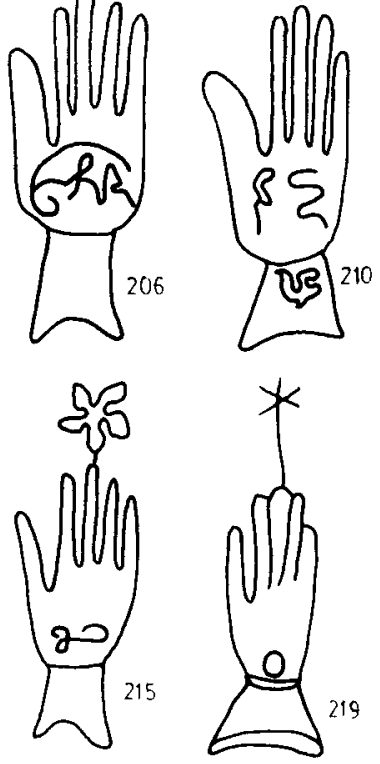

88
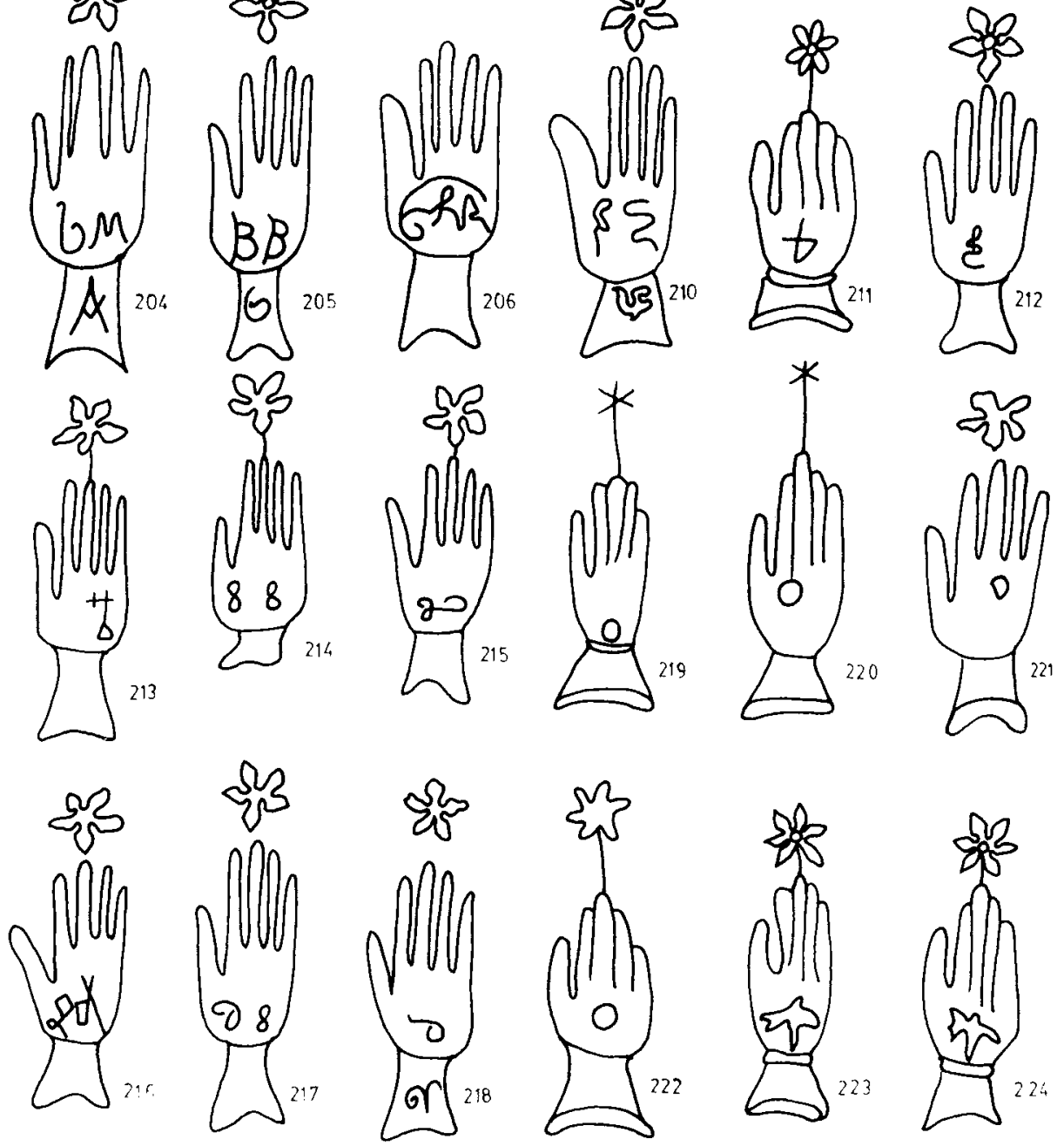

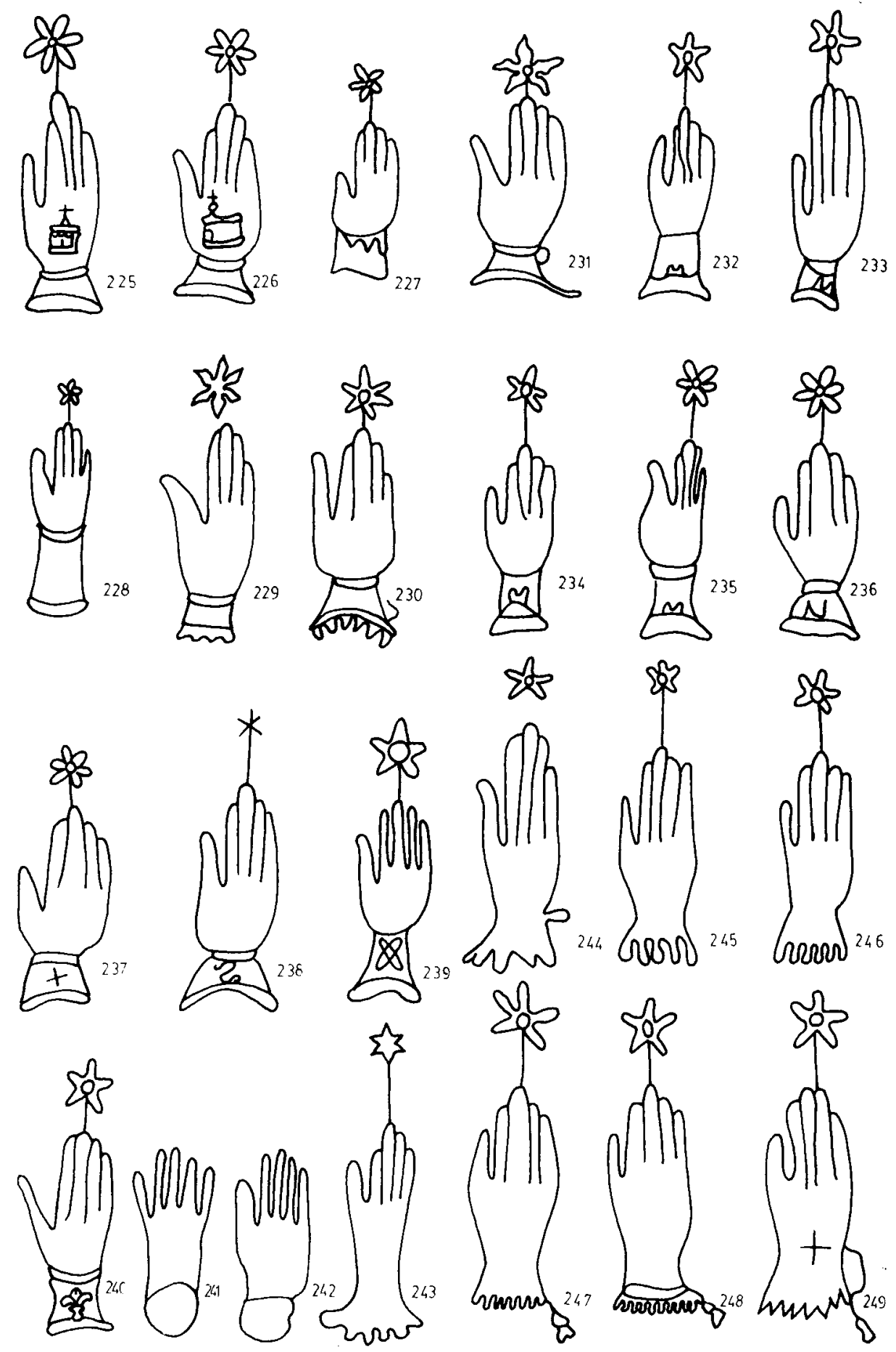

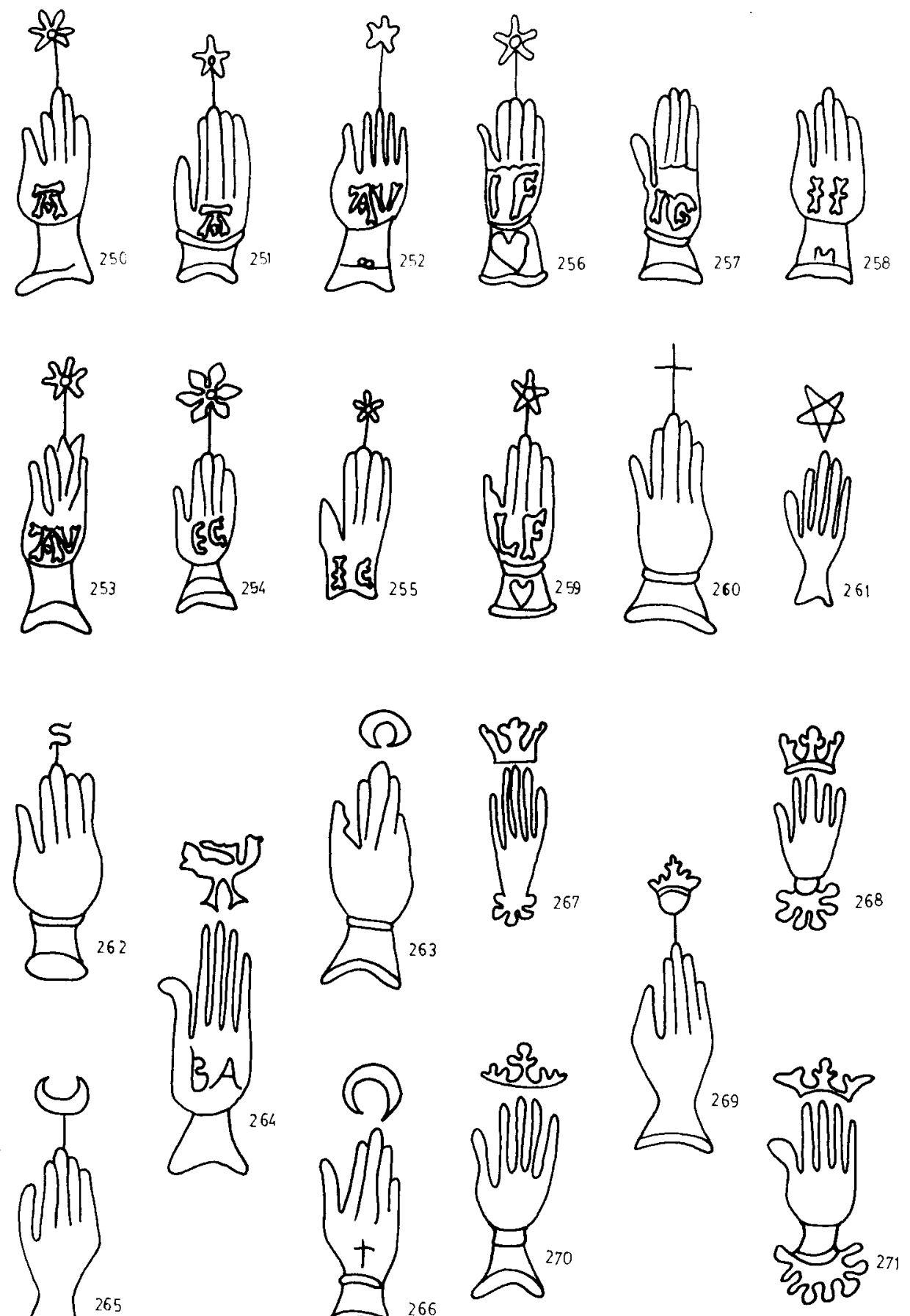

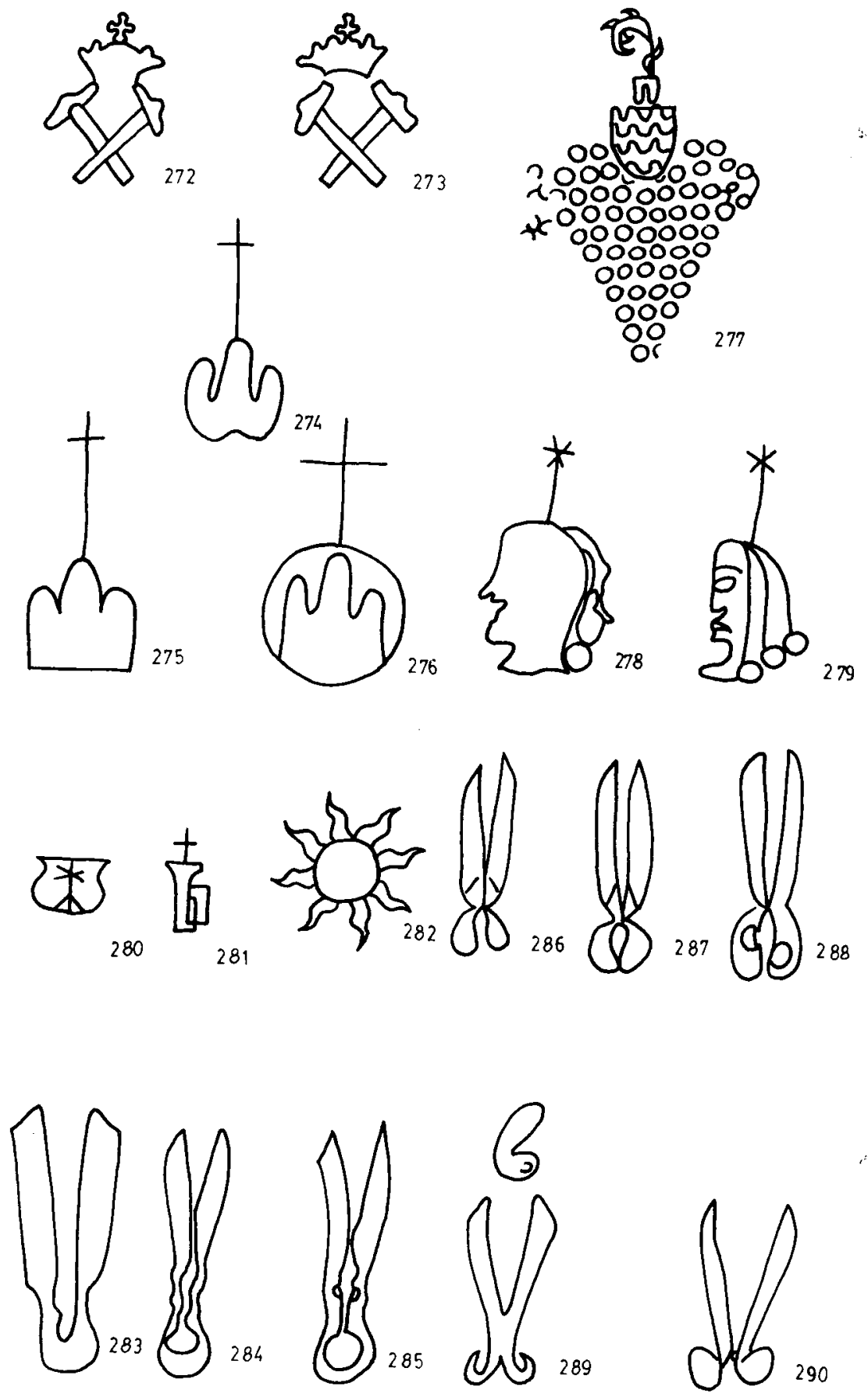

431 

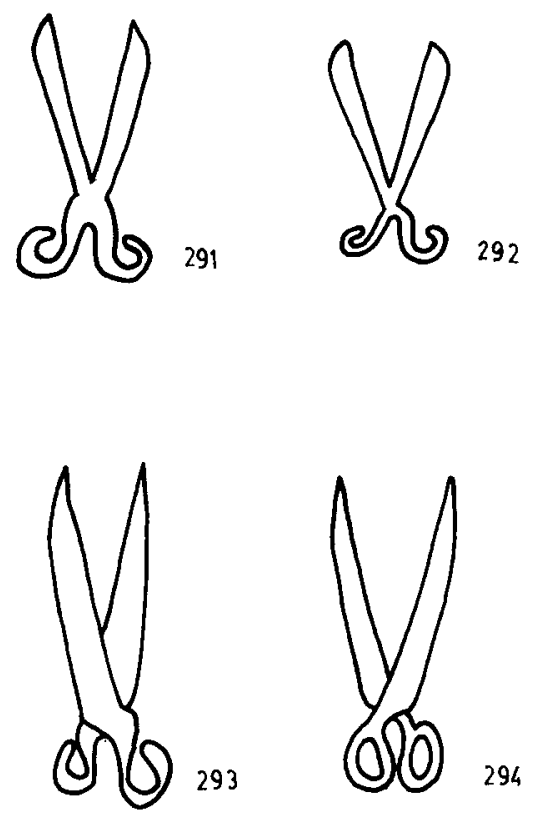

432 


\section{ANEXO III}

FIGURA CÓRDOBA

\begin{tabular}{|c|c|c|c|c|}
\hline TIPO & NÚMERO & FECHA & LOCALIDAD. FECHA & AUTOR. NÚMERO \\
\hline ANCLA & 1 & 1492 & $\begin{array}{l}\text { ITALIA. } 1490-92 \\
\text { SUECA. } 1492\end{array}$ & Briquet. 457 \\
\hline ANILLO & 5 & 1484 & $\begin{array}{l}\text { PIAMONTE. } 1483 \\
\text { CASTELLÓN. } 1480 \\
\text { MOSQUERUELA. } 1481\end{array}$ & $\begin{array}{l}\text { Briquet. } 692 \\
\text { López. } 6 \\
\text { Ariño. } 46\end{array}$ \\
\hline ÁGUILA & 19 & 1542 & MILÁN. 1541 & Briquet. 912 \\
\hline BUEY & 25 & 1512 & ALEMANIA. $1506-20$ & Briquet. 15445 \\
\hline BUEY & 26 & 1478 & TARRAGONA. 1437 & Sánchez Real. 5 \\
\hline CANDELABRO & 29 & 1492 & $\begin{array}{l}\text { LYON. } 1476 \\
\text { VILLARREAL. } 1464\end{array}$ & $\begin{array}{l}\text { Briquet. } 4364 \\
\text { Doñate. } 66\end{array}$ \\
\hline CARRO & 32 & 1449 & MOSQUERUELA. 1450 & Ariño. 120 \\
\hline CARRO & 33 & 1435 & LUCCA. 1434 & Briquet. 3544 \\
\hline CARRO & 35 & 1460 & $\begin{array}{l}\text { VILLARREAL. } 1465 \\
\text { JÁTIVA. } 1453 \\
\text { MOSQUERUELA. } 1460\end{array}$ & $\begin{array}{l}\text { Doñate. } 46 \\
\text { Cabanes. } 43 \\
\text { Ariño. } 94\end{array}$ \\
\hline CASTILLO & 36 & 1480 & $\begin{array}{l}\text { NÁPOLES. } 1469 \\
\text { VILLARREAL. } 1466-67 \\
\text { JÁTIVA. } 1498\end{array}$ & $\begin{array}{l}\text { Briquet. } 15913 \\
\text { Doñate. } 52 \\
\text { Cabanes. } 52\end{array}$ \\
\hline CRUZ & 53 & 1524 & FRANCIA. 1561 & Briquet. 5681 \\
\hline ESCUDO & 56 & - & HAMBURGO. 1494 & Briquet. 1660 \\
\hline FLOR & 63 & 1514 & $\begin{array}{l}\text { ZARAGOZA. } 1518 \\
\text { CASTELLÓN. } 1474 \\
\text { VILLARREAL. } 1491 \\
\text { JÁTIVA. } 1494 \\
\text { SUECA. } 1493\end{array}$ & $\begin{array}{l}\text { Briquet. } 6665 \\
\text { López. } 62 \\
\text { Doñate. } 92 \\
\text { Cabanes. } 69 \\
\text { Cortes. } 30\end{array}$ \\
\hline
\end{tabular}


FIGURA CÓRDOBA

\begin{tabular}{|c|c|c|c|c|}
\hline TIPO & NÚMERO & $\mathrm{FECHA}$ & LOCALIDAD. FECHA & AUTOR. NÚMERO \\
\hline FLOR & 66 & 1496 & ITALIA. 1435-63 & Briquet. 6640 \\
\hline FLOR & 68 & 1454 & MURCIA, 1454 & Abellán. 87 \\
\hline IGLESIA & 77 & 1486 & VILLARREAL. 1483 & Doñate. 105 \\
\hline LETRAS & 83 & 1516 & CARPENTRAS. 1523 & Briquet. 9070 \\
\hline LETRAS & 84 & 1492 & PALERMO. 1484 & Briquet. 9648 \\
\hline LOBO & 85 & 1464 & TARRAGONA. 1464 & Sánchez Real. 20 \\
\hline MANO & 124 & 1522 & NAMUR. 1530 & Briquet. 11428 \\
\hline MANO & 133 & 1554 & TOURS. 1548 & Briquet. 11245 \\
\hline MANO & 156 & 1514 & GÉNOVA. 1528 & Briquet. 10748 \\
\hline MANO & 195 & 1532 & GÉNOVA. 1549 & Briquet. 10736 \\
\hline MANO & 203 & 1540 & SIRACUSA. 1529 & Briquet. 10739 \\
\hline \multirow[t]{3}{*}{ MANO } & 226 & - & PERPIÑÁN. 1501 & Briquet. 11186 \\
\hline & & & VILLARREAL. 1496 & Doñate. 130 \\
\hline & & & MOSQUERUELA. 1487 & Ariño. 268 \\
\hline \multirow[t]{2}{*}{ MANO } & 230 & 1492 & PALERMO. 1487 & Briquet. 11135 \\
\hline & & & CASTELLÓN. 1487-92 & López, 97 \\
\hline \multirow[t]{2}{*}{ MANO } & 231 & 1490 & PALERMO. 1482 & Briquet. 11158 \\
\hline & & & CASTELLÓN. 1486-89 & López. 90 \\
\hline MANO & 240 & 1514 & BURGOS. 1515 & Briquet. 11187 \\
\hline MANO & 248 & 1492 & CASTELLÓN. $1487-89$ & López. 96 \\
\hline \multirow[t]{2}{*}{ MANO } & 249 & 1492 & CASTELLÓN. 1491-93 & López. 98 \\
\hline & & & MOSQUERUELA. 1493 & Ariño. 281 \\
\hline MANO & 251 & 1522 & BURGOS. 1523 & Briquet. 11189 \\
\hline MANO & 269 & 1484 & MOSQUERUELA. 1478 & Ariño. 226 \\
\hline MARTILLO & 272 & 1496 & FRANCIA. $1460-90$ & Briquet. 11638 \\
\hline MARTILLO & 273 & 1492 & FRANCIA. $1460-90$ & Briquet. 11639 \\
\hline MONTE & 274 & 1429 & MURCIA. 1429 & Abellán. 137 \\
\hline MONTE & 276 & 1450 & MURCIA. 1431 & Abellán. 141 \\
\hline RACIMO & 277 & 1514 & NANTES. $1507-40$ & Briquet. 13120 \\
\hline \multirow[t]{2}{*}{ ROSTRO } & 278 & 1492 & CASTELLÓN. 1489 & López. 26 \\
\hline & & & JÁTIVA. 1500 & Cabanes. 32 \\
\hline ROSTRO & 279 & 1518 & NIMES. 1533 & Briquet. 15695 \\
\hline TIJERAS & 283 & 1480 & GÉNOVA. 1452 & Briquet. 3762 \\
\hline TIJERAS & 286 & 1478 & VILLARREAL. 1485 & Doñate. 162 \\
\hline TIJERAS & 292 & 1490 & MOSQUERUELA. 1489 & Ariño. 329 \\
\hline
\end{tabular}

